\title{
The relationship between body temperature, heart rate, breathing rate, and rate of oxygen consumption, in the tegu lizard (Tupinambis merianae) at various levels of activity
}

\author{
Joanna Piercy $^{1} \cdot$ Kip Rogers $^{1} \cdot$ Michelle Reichert $^{1} \cdot$ Denis V. Andrade $^{2} \cdot$ \\ Augusto S. Abe ${ }^{2} \cdot$ Glenn J. Tattersall $^{3} \cdot$ William K. Milsom $^{1}$
}

Received: 8 April 2015 / Revised: 8 July 2015 / Accepted: 31 July 2015 / Published online: 19 August 2015

(C) Springer-Verlag Berlin Heidelberg 2015

\begin{abstract}
The present study determined whether EEG and/or EMG recordings could be used to reliably define activity states in the Brazilian black and white tegu lizard (Tupinambis merianae) and then examined the interactive effects of temperature and activity states on strategies for matching $\mathrm{O}_{2}$ supply and demand. In a first series of experiments, the rate of oxygen consumption $\left(\dot{V}_{\mathrm{O}_{2}}\right)$, breathing frequency $\left(f_{\mathrm{R}}\right)$, heart rate $\left(f_{\mathrm{H}}\right)$, and EEG and EMG (neck muscle) activity were measured in different sleep/ wake states (sleeping, awake but quiet, alert, or moving). In general, metabolic and cardio-respiratory changes were better indictors of the transition from sleep to wake than were changes in the EEG and EMG. In a second series of experiments, the interactive effects of temperature (17, 27 and $\left.37{ }^{\circ} \mathrm{C}\right)$ and activity states on $f_{\mathrm{R}}$, tidal volume $\left(V_{\mathrm{T}}\right)$, the fraction of oxygen extracted from the lung per breath $\left(\mathrm{FI}_{\mathrm{O} 2}-\mathrm{FE}_{\mathrm{O} 2}\right), f_{\mathrm{H}}$, and the cardiac $\mathrm{O}_{2}$ pulse were quantified to determine the relative roles of each of these variables in accommodating changes in $\dot{V}_{\mathrm{O}_{2}}$. The increases in oxygen supply to meet temperature- and activity-induced increases in oxygen demand were produced almost exclusively by increases in $f_{\mathrm{H}}$ and $f_{\mathrm{R}}$. Regression analysis showed that the effects of temperature and activity state on the relationships
\end{abstract}

Communicated by G. Heldmaier.

William K. Milsom

milsom@zoology.ubc.ca

1 Department of Zoology, University of British Columbia, 6270 University Boulevard, Vancouver, BC V6T 1Z4, Canada

2 Depto de Zoologia, Instituto Nacional de Ciência e Tecnologia em Fisiologia Comparada, Univ Estadual Paulista-Rio Claro, Rio Claro, SP, Brazil

3 Department of Biological Sciences, Brock University, St Catharines, ON, Canada between $f_{\mathrm{H}}, f_{\mathrm{R}}$ and $\dot{V}_{\mathrm{O}_{2}}$ was to extend a common relationship along a single curve, rather than separate relationships for each metabolic state. For these lizards, the predictive powers of $f_{\mathrm{R}}$ and $f_{\mathrm{H}}$ were maximized when the effects of changes in temperature, digestive state and activity were pooled. However, the best $r^{2}$ values obtained were 0.63 and 0.74 using $f_{\mathrm{R}}$ and $f_{\mathrm{H}}$ as predictors of metabolic rate, respectively.

Keywords Body temperature $\cdot$ Heart rate $\cdot$ Breathing rate $\cdot$ Metabolic rate $\cdot$ Tegu lizard

\section{Introduction}

The black and white tegu lizard (Tupinambis merianae) has been the focus of several metabolic studies, including the metabolic responses to exercise and feeding (Skovgaard and Wang 2004; Klein et al. 2006), the metabolic effects of changes in age, body size and season (Toledo et al. 2008), metabolic acclimation at constant temperature and photoperiod across seasons (Abe 1995; Milsom et al. 2008), and metabolic depression during seasonal dormancy (Abe 1983, 1995; Andrade and Abe 1999; de Souza et al. 2004). The most important factors influencing metabolic rate during dormancy in lizards in the field are reductions in temperature and activity.

In reptiles, it is often difficult to determine whether animals are dormant, asleep, or resting quietly (i.e., awake with eyes closed). The use of EEG and EMG recordings in reptiles to distinguish activity states has produced conflicting results (Flanigan et al. 1973; Warner and Huggins 1978; Meglasson and Huggins 1979; Walker and Berger 1973; Ayala-Guerrero et al. 1988; Tauber et al. 1968; 
Huntley 1987; Flanigan 1973; Ayala-Guerrero and HuitronResendiz 1991). Although these different states may be difficult to distinguish visually or electrophysiologically, one would expect metabolism to be higher in animals when awake than when sleeping (Wood et al. 1978; Hicks and Riedesel 1983; Revell and Dunbar 2007), and to be suppressed below sleeping levels during dormancy. If this is true, one may be able to use metabolic rate [and potentially breathing frequency $\left(f_{\mathrm{R}}\right)$ or heart rate $\left.\left(f_{\mathrm{H}}\right)\right]$ to distinguish between different activity states. Our first objective, therefore, was to determine the extent to which electrophysiological, behavioral and metabolic changes could be used to determine changes in activity state.

The changes in metabolic demands for oxygen associated with changes in temperature and activity may be met in a variety of ways. The two convective steps in the oxygen transport cascade are ventilation and perfusion. Thus, changes in any of ventilatory flow (altering breathing frequency and/or tidal volume), oxygen extraction from inspired air, cardiac output (altering heart rate and/or stroke volume) and oxygen extraction from the circulating blood may be recruited for this purpose. Our second objective was to quantify the interactive effects of temperature (17, 27 and $37{ }^{\circ} \mathrm{C}$ ) and activity states on these various strategies used by tegu lizards for matching $\mathrm{O}_{2}$ supply and demand.

\section{Methods}

Two series of experiments were performed. The first used four juvenile tegu lizards (Tupinambis meriannae) $<3$ years of age ranging from 630 to $950 \mathrm{~g}$, while the second series used six tegu lizards (three male and three female), each approximately 3-4 years of age with weights ranging from 2.2 to $3.9 \mathrm{~kg}$. All lizards were bred in Brazil at the Jacarezario, UNESP, Bela Vista Campus, Rio Claro, SP. Animals were brought to the University of British Columbia within a few weeks of hatching and raised in captivity. All experimental procedures conformed to and were approved by the UBC animal care and use committee.

\section{Series 1}

\section{Instrumentation}

In the first series of experiments animals were anesthetized with $2.5 \%$ halothane in air and four $0.65 \mathrm{~mm}$ holes were drilled bilaterally into the skull above the positions of the posterior telencephalon and the mid optic tectum. Four self-tapping screws (1.2 $\mathrm{mm}$ diameter, $6 \mathrm{~mm}$ length) were threaded into the holes and fixed to the skull with acrylic cement. Braided stainless steel coated wires $(0.25 \mathrm{~mm})$ housed in a thin silastic tube were passed externally to an amphenol pin strip sutured to the skin above the forelimbs to serve as EEG electrodes for chronic recording. EMG and ECG electrodes were passed subdermally to the amphenol pin strip. The EMG electrodes were attached bilaterally to the nuchal muscles of the neck just beneath the skin. ECG electrodes were placed on the lateral thorax on either side of the heart. Following surgery, the animals were given 10 days to recover and were individually housed under a 9:15 light-dark photoperiod. Instrumentation had no apparent effect on behavior and the leads did not impede locomotion.

\section{Experimental protocol}

Video recordings were used to score the behavior of lizards (sleep, awake, alert and active, see below) while recording the physiological variables. During recordings, tegus were housed in a circular metabolic chamber $(20 \mathrm{~cm}$ diameter $\times 10 \mathrm{~cm}$ high) placed in an insulated environmental chamber under a 9:15 h light-dark photoperiod at a constant temperature of $27{ }^{\circ} \mathrm{C}$. Red light was used during the scotopic period to permit digital video recording. Wire leads were connected from the amphenol pin strip to a commutator in the lid of the respirometer and then to a Grass polygraph recorder (model 79E) where signals were amplified and filtered $(60 \mathrm{~Hz}$ notch filter). Air was drawn through the respirometer and then through a drying column to oxygen and carbon dioxide analyzers (Models OM-11 and LB-2, Beckman Instruments, USA) at a rate of $180 \mathrm{ml} /$ $\mathrm{min}$. These instruments were automatically calibrated every $3 \mathrm{~h}$.

Lizards were initially habituated to recording conditions for $48 \mathrm{~h}$. They were then removed from the recording chamber and given water in their home chambers. Twentyfour hours later they were returned to the recording chamber and allowed a further $24 \mathrm{~h}$ to settle before recording trials began. Recordings were carried out over a minimum $24 \mathrm{~h}$ period beginning at 13:00 $\mathrm{h}$.

\section{Series 2}

\section{Instrumentation}

In these experiments, custom-fitted masks were made for each lizard as described by Glass et al. (1978) and modified by Wang and Warburton (1995). A pneumotachograph was mounted on top of the mask and connected to the oxygen and carbon dioxide analyzers and a differential pressure transducer (Model DP103-18, Validyne Engineering Corp, USA) and amplifier (Model 7P122E, Grass Instruments, USA) for measuring tidal volume and breathing frequency. Three ECG electrodes (gold plated, Grass Instruments, USA) were implanted subcutaneously in the thorax/ 
abdomen under anesthesia, triangulating the heart in order to monitor heart rate. The electrodes were sutured and glued in place and the lizards were allowed to recover for at least $24 \mathrm{~h}$ before any experimental runs.

\section{Experimental protocol}

Experiments involved four treatments: $17{ }^{\circ} \mathrm{C} /$ fasting, $27{ }^{\circ} \mathrm{C} /$ fasting, $37{ }^{\circ} \mathrm{C} /$ fasting, and $37{ }^{\circ} \mathrm{C} /$ digesting. Each trial lasted $3 \mathrm{~h}$ during the active period (lights on), and was followed by a minimum $24 \mathrm{~h}$ period as animals were acclimated to the next treatment temperature. Temperature treatments were randomized, but the digesting trial was always carried out as the final trial.

At the start of each trial, the outflow tubes from the pneumotachograph were connected to the gas analyzers and to the differential pressure transducer. ECG leads were connected to the amplifier (Grass Instruments, USA, Model 7P511K,). The dead space of the mask was small enough that individual breaths were resolvable and end tidal values for $\mathrm{O}_{2}$ and $\mathrm{CO}_{2}$ were easily observed. The lizard's posture and activities were recorded with a VCR, and were associated with the corresponding physiological data during analysis.

After each trial, the mask was removed and the lizard was offered water and kept in the environmental chamber while acclimating to the next treatment temperature. Prior to the $37{ }^{\circ} \mathrm{C} /$ digesting trial, the lizard was offered a standard meal of ground beef, vegetables, fruit and vitamin and mineral supplements and was allowed to feed to satiation; lizards never ate more than $4 \%$ of their body weight (roughly 100-150 g) despite being fasted for several weeks. Data collection typically began approximately $36-40 \mathrm{~h}$ later as this is approximately when specific dynamic action reaches its peak in tegu lizards (Skovgaard and Wang 2004; Klein et al. 2006).

\section{Data analysis}

\section{Series 1}

The EEG, EMG, and ECG signals, along with the output of the $\mathrm{O}_{2}$ and $\mathrm{CO}_{2}$ analyzers, were recorded to computer at $240 \mathrm{~Hz}$ using a Windaq data acquisition system (DI200; DataQ Instruments, Akron, OH, USA). Twenty one-minute epochs were randomly chosen from each behavioral state in each animal for analysis. From these traces, we calculated EEG and EMG amplitude and performed a frequency analysis on the EEG signals using both visual analysis as well as a windowed fast fourier transformation. Frequencies ranging from 1 to $33 \mathrm{~Hz}$ were analyzed in $1 \mathrm{~Hz}$ bands to assess the EEG frequencies associated with each state. Rates of oxygen consumption and $\mathrm{CO}_{2}$ production $\left(\dot{V}_{\mathrm{O}_{2}}\right.$ and $\dot{V}_{\mathrm{CO}_{2}}$, respectively) were obtained by integrating the area under the $\mathrm{O}_{2}$ and $\mathrm{CO}_{2}$ curves and were corrected according to Withers (1977). Given the range in body mass of the lizards, to characterize the relationship between mass and resting oxygen consumption, all metabolic data were scaled to the power of 0.79 as derived for tegu lizards by Toledo et al. (2008). Ventilation rate was determined from phasic EMG activity arising from the intercostal muscles and appearing on the ECG trace.

\section{Series 2}

In these series, treatments were applied using a repeatedmeasures design. The output of the $\mathrm{O}_{2}$ and $\mathrm{CO}_{2}$ analyzers, the electrocardiogram (ECG) and the differential pressure across the pneumotachograph were also recorded to computer at $240 \mathrm{~Hz}$. From these signals, it was possible to calculate $\dot{V}_{\mathrm{O}_{2}}$ and $\dot{V}_{\mathrm{CO}_{2}}$ (reported at STPD), $f_{\mathrm{H}}, f_{\mathrm{R}}$ and $V_{\mathrm{T}}$. Ventilation volume $\left(\dot{V}_{\mathrm{E}}\right)$ was calculated as the product of $f_{\mathrm{R}}$ and $V_{\mathrm{T}}$ and cardiac $\mathrm{O}_{2}$ pulse was calculated as $\dot{V}_{\mathrm{O}_{2}}$ divided by $f_{H}$.

All data from the experiments in series 2 were analyzed using 5 min samples of data taken approximately every $10 \mathrm{~min}$. In both series, the first data sample was taken at least $30 \mathrm{~min}$ after commencing recording, and all samples were taken during steady state conditions.

\section{Statistical analysis}

In series 1, all variables in each state were compared using a repeated-measures ANOVA and a student $t$ test was used for intergroup comparisons. All data reported as percent change were arcsine transformed prior to analysis. In series 2 , for each protocol, the means for each variable were compared via a 2-way repeated measures ANOVA with treatment and activity as the two effects, followed by post hoc Holm-Sidak tests to identify specific differences. The effect of temperature was tested using averages from $17^{\circ} \mathrm{C} /$ fasting, $27{ }^{\circ} \mathrm{C} /$ fasting and $37{ }^{\circ} \mathrm{C} /$ fasting experiments, while the effect of digestion was tested on averages from $37^{\circ} \mathrm{C} /$ fasting and $37{ }^{\circ} \mathrm{C} /$ digesting experiments. Sleep data were excluded from statistical analysis of this series due to low sample size.

All statistics were performed using SigmaStat 3.1 and JMPIN 4.0.4. Results were considered significant if $P<0.05$.

\section{Results}

\section{Series 1}

Observations and measurements were made in Series 1 to determine whether objective electrophysiological criteria 
Fig. 1 Four, $10 \mathrm{~s}$ sample traces of EEG and EMG signals during wake $(\mathbf{a}, \mathbf{c})$ and sleep $(\mathbf{b}$, d). While the amplitude of the EMG trace is clearly reduced in sleep, differences in the EEG traces were not always evident (compare $\mathbf{a}$ vs $\mathbf{b}$ with $\mathbf{c}$ vs $\mathbf{d}$ )
A

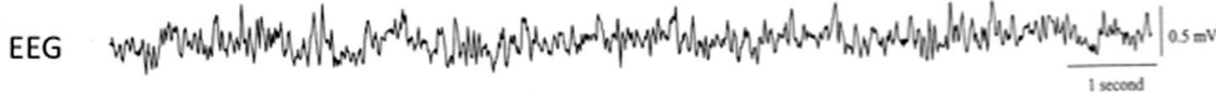
EMG

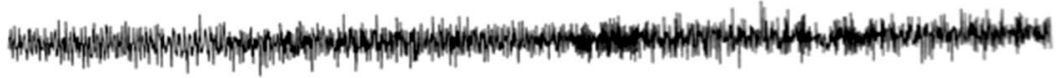

B EEG EMG

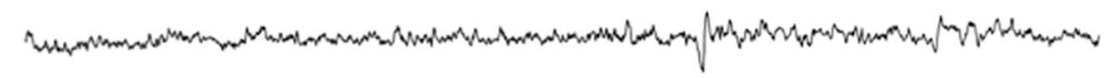

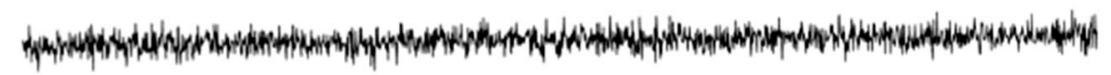

C EEG

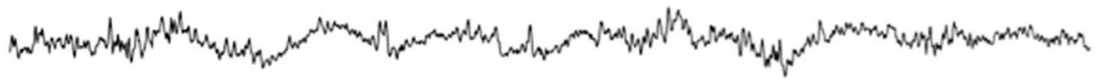
EMG

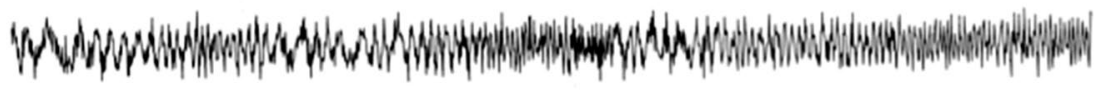

$\mathbf{D}_{\text {EEG }}$

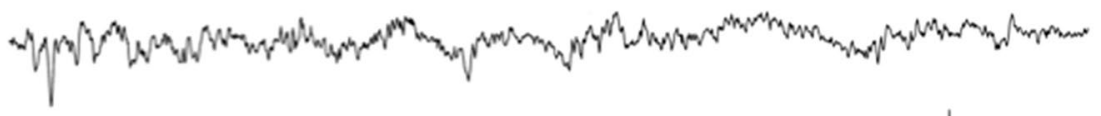

EMG could identify activity states based on behavioral criteria; particularly sleep and quiet wake.

Behavioral states were first classified based on the criteria proposed by Huntley (1987). During sleep, animals lay motionless with head and thorax in contact with the substrate, the palmar surfaces of the forelimbs facing up, and the palmar surfaces of the hindlimbs facing the body. During quiet wake, animals also lay motionless with their thorax and head on the substrate but with their forelimbs splayed laterally from the body with palmar surfaces down and hindlimbs extended to the side. We categorized animals as alert when their eyes were open and/or their body was held up off the floor, or when they were resting between periods of activity. All animals displaying any form of movement were categorized as "moving".

Figure 1 illustrates EEG and EMG traces taken from one animal during two different episodes of alert wake (Fig. 1a, c) and sleep (Fig. 1b, d) while Fig. 2 presents the EEG power spectral analysis for longer segments of these same four episodes from this animal. No distinct EEG frequency bands were associated with either state. In both states, periods dominated by slower frequencies (Figs. 1c, d, 2c, d) alternated with periods with higher frequencies (Figs. 1a, $\mathrm{b}, 2 \mathrm{a}, \mathrm{b})$. The only notable difference between states was in the absolute value of power spectral density reflecting the lower amplitude of the EEG in sleep (Fig. 2). Similar results were obtained from all other lizards.

Figure 3 presents the quantitative physiological data for all four animals. EEG amplitude fell significantly
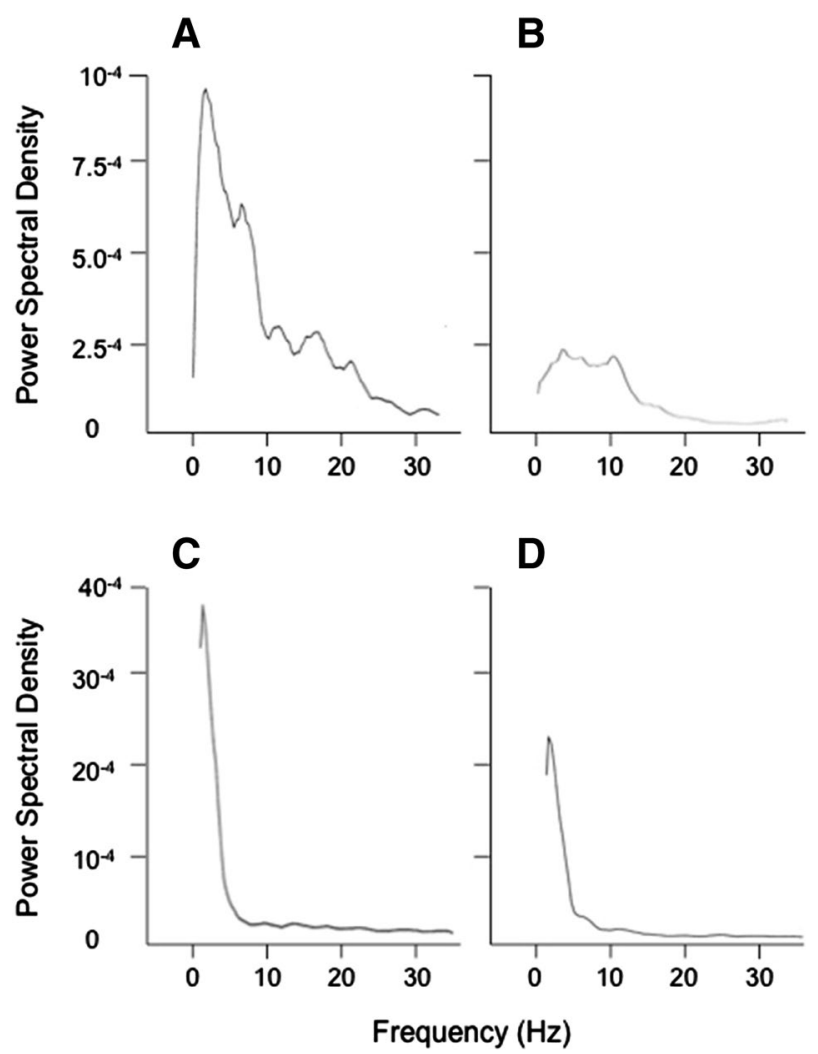

Fig. 2 EEG power spectral density of 16-second epochs during both wake and sleep. a Period of wake with high frequency activity; b period of sleep with high frequency activity; c period of wake with low frequency activity; $\mathbf{d}$ period of sleep with low frequency activity 
Fig. 3 Effects of sleep vs wake on a EEG amplitude, b EMG amplitude, $\mathbf{c}$ oxygen consumption, $\mathbf{d ~ C O}$ production (all expressed as \% change relative to alert), $\mathbf{e}$ heart rate and $\mathbf{f}$ breathing frequency. Asterisk indicates significantly different from alert. Plus sign (+) indicates significantly different from wake
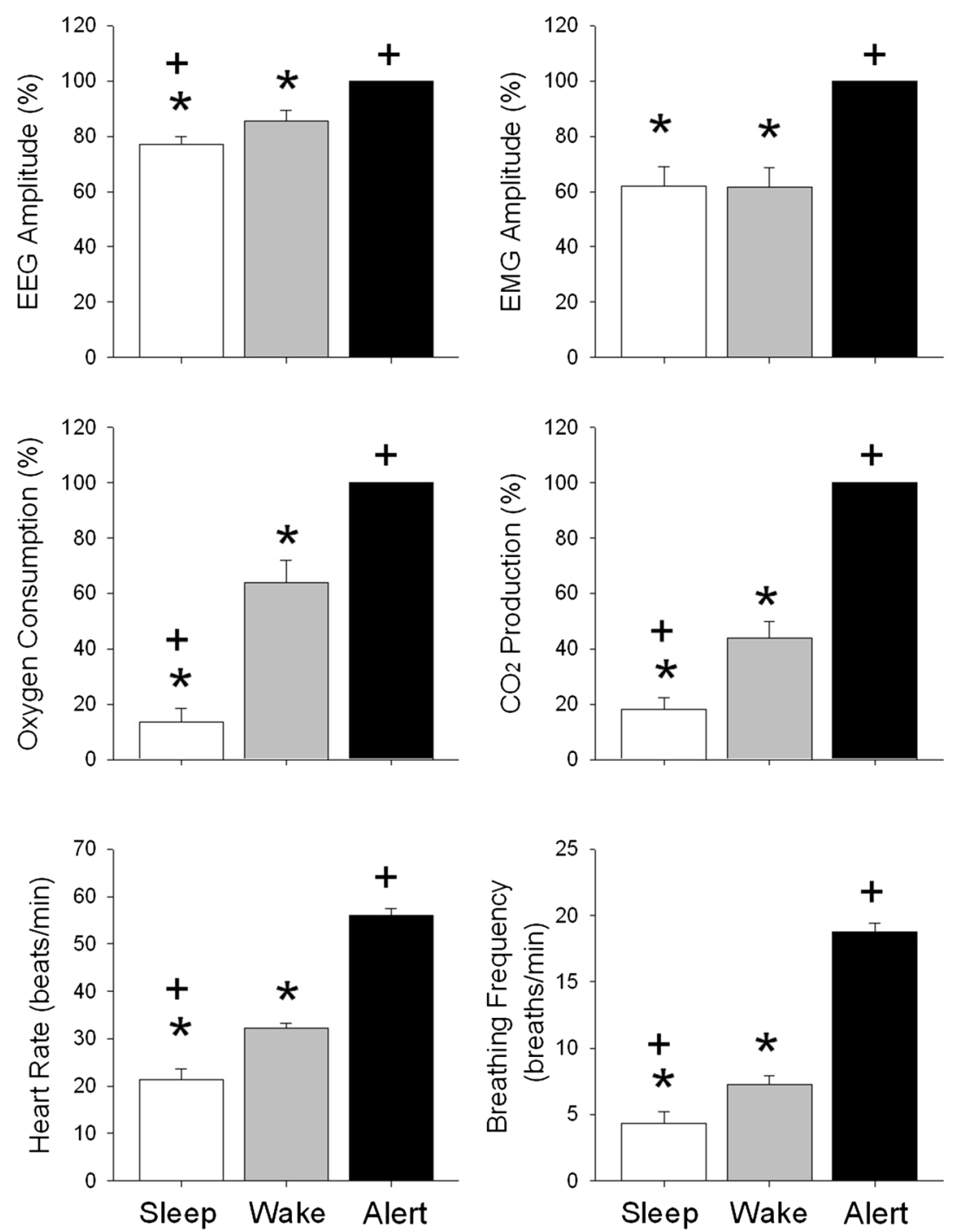

from alert to wake and from wake to sleep (Fig. 3). In contrast, EMG amplitude only fell from alert to awake activity states (Fig. 3). $\dot{V}_{\mathrm{O}_{2}}, \dot{V}_{\mathrm{CO}_{2}}, f_{\mathrm{H}}$ and $f_{\mathrm{R}}$ all fell significantly with each step from alert to quiet wake to sleep (Fig. 3).

\section{Series 2}

Graphic representations of the mean values of $\dot{V}_{\mathrm{O}_{2}}, f_{\mathrm{H}}$, and the cardiac $\mathrm{O}_{2}$ pulse are presented in Fig. 4, illustrating the effects of temperature and activity. Oxygen consumption and $f_{\mathrm{H}}$ increased significantly as the animals progressed from quiet wake to alert and moving at all temperatures. Lizards also consumed more oxygen and increased heart rate with increasing temperature in all activity states (Fig. 4; Table 1). The changes in mean values of the cardiac $\mathrm{O}_{2}$ pulse with increasing activity were qualitatively different depending on the temperature (Fig. 4; Table 1).

Graphic representations of the mean values of each variable in the Fick equation for oxygen transport by ventilatory convection are presented in Fig. 5 and Table 1. Breathing frequency increased significantly with increasing activity at all temperatures and also increased with increasing temperature except going from 27 to $37^{\circ} \mathrm{C}$ during movement (Fig. 5; Table 1). Mean values for $V_{\mathrm{T}}$ did not change significantly with increasing activity or temperature. Oxygen extraction generally decreased with increasing activity at all temperatures (although this was only significant during movement) and there was no significant change with changing temperature within any activity state (Fig. 5; Table 1).

Table 2 depicts the effect of temperature on $\dot{V}_{\mathrm{O}_{2}}, \dot{V}_{\mathrm{CO}_{2}}$, $f_{\mathrm{H}}$, and $f_{\mathrm{R}}$. As is apparent from Figs. 4 and 5, the largest 


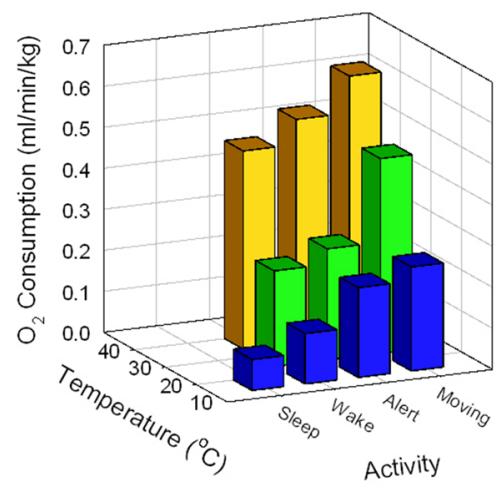

$\dot{\mathrm{V}}_{2}$

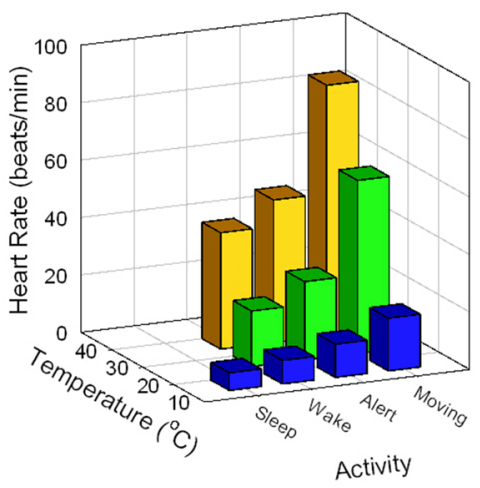

$=\quad f_{H} \quad x$

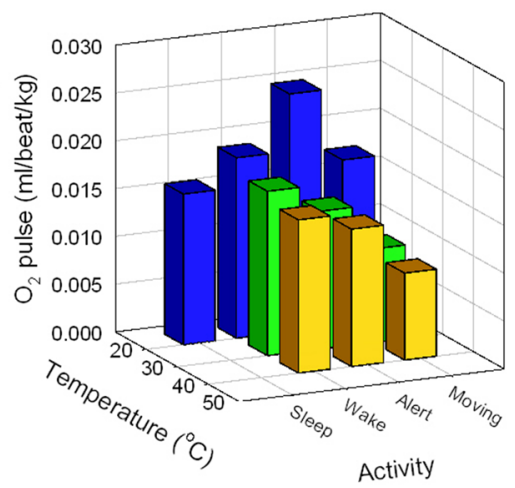

$\mathrm{O}_{2}$ pulse

Fig. 4 Mean values of each variable in Fick's equation for oxygen transport by circulatory convection (rate of oxygen consumption $=$ heart rate $\times$ the cardiac $\mathrm{O}_{2}$ pulse) as a function of temperature and activity state (see Table 1 for statistics)

increases with temperature were seen in $f_{\mathrm{H}}$ and $f_{\mathrm{R}}$. The $Q_{10}$ values were generally close to 2 and similar at the transition from 17 to $27^{\circ} \mathrm{C}$ and from 27 to $37^{\circ} \mathrm{C}$.

Mean values of each variable from digesting animals at $37{ }^{\circ} \mathrm{C}$ were not statistically different from those of fasting animals at $37^{\circ} \mathrm{C}$ (Table 1$)$.

\section{Heart rate vs $\mathrm{O}_{2}$ consumption}

Figure 6 shows all mass-specific $\mathrm{O}_{2}$ consumption data grouped by treatment (Fig. 6a) and activity (Fig. 6b), plotted against heart rate. Independent regressions were calculated for each lizard at each temperature (not shown) and 22 out of 24 proved to be significant. All slopes were statistically different in all treatments except $17{ }^{\circ} \mathrm{C} /$ fasting animals and intercepts were significantly different in all treatments. This allowed pooled regressions (i.e., the combination of data from multiple runs for a single individual) to be calculated for each treatment (as in Bevan et al. 1994, 1995). Pooled regressions for all lizards at each temperature (not shown) were significant in all cases, but there was still much variation not accounted for by the regressions (the $r^{2}$ values ranged from 0.30 in $37{ }^{\circ} \mathrm{C} /$ fasting animals, to 0.63 in $17{ }^{\circ} \mathrm{C} /$ fasting animals). When pooled regressions were performed using activity as a grouping factor individual regressions were significant at each activity level (18 of 18 regressions had $P<0.05$ ) and values of $r^{2}$ ranged from 0.47 to 0.66 . Finally, all data (for all treatments and activities) were pooled to perform one last regression analysis. Linear regressions were carried out on untransformed and transformed data, and the primary regression variables for each are shown in Table 3. All regressions were significant and transforming the data produced better regressions. When both $f_{\mathrm{H}}$ and $\mathrm{O}_{2}$ consumption were natural log-transformed, $74 \%$ of the variability in $\mathrm{O}_{2}$ consumption could be accounted for by changes in heart rate (Fig. 6).

\section{Breathing frequency vs $\mathrm{O}_{2}$ consumption}

The same regression analysis was performed on $f_{\mathrm{R}}$ data as on the $f_{\mathrm{H}}$ data and the key results are presented in Fig. 7 and Table 4. All regressions were significant, but in all cases, $r^{2}$ values were lower compared with regressions using $f_{\mathrm{H}}$ (see Table 3). Again, transforming the data produced better regressions. When both $f_{\mathrm{R}}$ and $\mathrm{O}_{2}$ consumption were logtransformed, the regression could account for $63 \%$ of the variability in $\mathrm{O}_{2}$ consumption.

\section{Discussion}

\section{Electrophysiological correlates of wake and sleep}

The transition from quiet wake to sleep was accompanied by a significant, but small decrease in EEG amplitude (roughly $5 \%$ ) and no change in EMG amplitude. These findings are in general agreement with previous studies of other reptilian species including crocodilians (Flanigan et al. 1973; Warner and Huggins 1978; Meglasson and Huggins, 1979), chelonians (Walker and Berger 1973; AyalaGuerrero et al. 1988) and other species of lizards (Tauber et al. 1968; Huntley 1987; Flanigan 1973; Ayala-Guerrero and Huitron-Resendiz 1991). We also did not find any distinct EEG frequency bands accompanying either the wake or sleep states. The hallmark of sleep in most mammals is the switch from a low amplitude, high frequency EEG pattern to a high amplitude pattern of slow waves (Rechtschaffen et al. 1968). While some researchers have reported a 
Table 1 Mean values of all variables measured in Series 2

\begin{tabular}{|c|c|c|c|c|c|}
\hline Variable & Activity & $17^{\circ} \mathrm{C}$ & $27^{\circ} \mathrm{C}$ & $37^{\circ} \mathrm{C}$ & $37^{\circ} \mathrm{C}+$ food \\
\hline \multirow[t]{4}{*}{$\mathrm{O}_{2}$ consumption $(\mathrm{ml} / \mathrm{min} / \mathrm{kg})$} & Sleep & $0.08 \pm 0.01^{\mathrm{a}}$ & - & - & - \\
\hline & Wake & $0.12 \pm 0.02^{\mathrm{b}}$ & $0.23 \pm 0.05$ & $0.48 \pm 0.03^{\mathrm{b}}$ & $0.40 \pm 0.03$ \\
\hline & Alert & $0.22 \pm 0.03^{\mathrm{a}, \mathrm{b}}$ & $0.27 \pm 0.05^{\mathrm{a}}$ & $0.54 \pm 0.04^{\mathrm{a}, \mathrm{b}}$ & $0.52 \pm 0.06^{\mathrm{a}}$ \\
\hline & Moving & $0.25 \pm 0.03^{\mathrm{a}, \mathrm{b}}$ & $0.48 \pm 0.08^{\mathrm{a}}$ & $0.63 \pm 0.06^{\mathrm{a}, \mathrm{b}}$ & $0.66 \pm 0.07^{\mathrm{a}}$ \\
\hline \multirow[t]{4}{*}{$\mathrm{CO}_{2}$ production $(\mathrm{ml} / \mathrm{min} / \mathrm{kg})$} & Sleep & $0.05 \pm 0.01^{\mathrm{a}}$ & - & - & - \\
\hline & Wake & $0.10 \pm 0.02^{\mathrm{b}}$ & $0.20 \pm 0.04$ & $0.34 \pm 0.04^{\mathrm{b}}$ & $0.29 \pm 0.03^{b}$ \\
\hline & Alert & $0.18 \pm 0.02^{\mathrm{a}, \mathrm{b}}$ & $0.28 \pm 0.05^{\mathrm{a}}$ & $0.41 \pm 0.03^{\mathrm{a}, \mathrm{b}}$ & $0.40 \pm 0.05^{\mathrm{a}, \mathrm{b}}$ \\
\hline & Moving & $0.28 \pm 0.03^{\mathrm{a}, \mathrm{b}}$ & $0.47 \pm 0.06^{\mathrm{a}}$ & $0.57 \pm 0.04^{\mathrm{a}, \mathrm{b}}$ & $0.56 \pm 0.05^{\mathrm{a}, \mathrm{b}}$ \\
\hline \multirow[t]{4}{*}{ Heart rate (beats/min) } & Sleep & $6.2 \pm 0.4$ & - & - & - \\
\hline & Wake & $8.2 \pm 1.0^{\mathrm{b}}$ & $19.3 \pm 4.6$ & $40.5 \pm 5.6^{\mathrm{b}}$ & $45.3 \pm 4.7^{b}$ \\
\hline & Alert & $11.6 \pm 1.8^{\mathrm{a}, \mathrm{b}}$ & $27.3 \pm 4.6$ & $49.7 \pm 3.6^{\mathrm{a}, \mathrm{b}}$ & $56.2 \pm 6.0^{\mathrm{a}, \mathrm{b}}$ \\
\hline & Moving & $18.4 \pm 1.8^{\mathrm{a}, \mathrm{b}}$ & $60.3 \pm 3.8^{\mathrm{a}}$ & $87.4 \pm 5.3^{\mathrm{a}, \mathrm{b}}$ & $89.4 \pm 7.1^{\mathrm{a}, \mathrm{b}}$ \\
\hline \multirow[t]{4}{*}{ Cardiac $\mathrm{O}_{2}$ pulse $(\mathrm{ml} / \mathrm{beat} / \mathrm{kg})$} & Sleep & $0.012 \pm 0.002$ & - & - & - \\
\hline & Wake & $0.015 \pm 0.002$ & $0.014 \pm 0.004$ & $0.013 \pm 0.001$ & $0.010 \pm 0.001$ \\
\hline & Alert & $0.020 \pm 0.002^{\mathrm{a}, \mathrm{b}}$ & $0.012 \pm 0.003$ & $0.011 \pm 0.001$ & $0.010 \pm 0.001$ \\
\hline & Moving & $0.014 \pm 0.001^{\mathrm{b}}$ & $0.008 \pm 0.001^{\mathrm{a}}$ & $0.007 \pm 0.000^{\mathrm{a}}$ & $0.007 \pm 0.001^{\mathrm{a}}$ \\
\hline \multirow[t]{4}{*}{ Tidal volume (ml) } & Sleep & $19.2 \pm 3.6$ & - & - & - \\
\hline & Wake & $16.8 \pm 2.0$ & $13.6 \pm 0.5$ & $12.2 \pm 1.4$ & $13.6 \pm 1.5$ \\
\hline & Alert & $18.0 \pm 1.6$ & $17.4 \pm 4.3$ & $12.9 \pm 1.9$ & $12.2 \pm 2.5$ \\
\hline & Moving & $15.3 \pm 1.3$ & $20.4 \pm 2.3$ & $17.2 \pm 1.4$ & $16.0 \pm 2.5$ \\
\hline \multirow[t]{4}{*}{ Breathing frequency (breaths/min) } & Sleep & $1.1 \pm 0.1^{\mathrm{a}}$ & - & - & - \\
\hline & Wake & $2.6 \pm 0.2^{b}$ & $7.0 \pm 1.6$ & $16.6 \pm 2.8^{\mathrm{b}}$ & $17.6 \pm 6.2$ \\
\hline & Alert & $7.8 \pm 1.6^{\mathrm{a}, \mathrm{b}}$ & $13.4 \pm 1.1^{\mathrm{a}}$ & $26.5 \pm 1.8^{\mathrm{a}, \mathrm{b}}$ & $29.6 \pm 4.2^{\mathrm{a}}$ \\
\hline & Moving & $25.9 \pm 1.1^{\mathrm{a}, \mathrm{b}}$ & $48.9 \pm 3.1^{\mathrm{a}}$ & $51.9 \pm 3.4^{\mathrm{a}}$ & $56.5 \pm 5.2^{\mathrm{a}}$ \\
\hline \multirow[t]{4}{*}{$\% \mathrm{O}_{2}$ extracted } & Sleep & $5.4 \pm 0.2$ & - & - & - \\
\hline & Wake & $4.1 \pm 0.1$ & $3.5 \pm 0.2$ & $3.5 \pm 0.1$ & $2.9 \pm 0.1$ \\
\hline & Alert & $2.2 \pm 0.1$ & $1.6 \pm 0.1$ & $2.4 \pm 0.1$ & $2.4 \pm 0.1$ \\
\hline & Moving & $0.9 \pm 0.1^{\mathrm{a}}$ & $0.7 \pm 0.0^{\mathrm{a}}$ & $1.1 \pm 0.0^{\mathrm{a}}$ & $1.1 \pm 0.1$ \\
\hline \multirow[t]{4}{*}{ Total ventilation $(\mathrm{ml} / \mathrm{min} / \mathrm{kg})$} & Sleep & $7 \pm 1^{\mathrm{a}}$ & - & - & - \\
\hline & Wake & $14 \pm 2^{b}$ & $31 \pm 8$ & $65 \pm 15^{b}$ & $66 \pm 16$ \\
\hline & Alert & $47 \pm 11^{\mathrm{a}, \mathrm{b}}$ & $79 \pm 25^{\mathrm{a}}$ & $106 \pm 13^{\mathrm{a}, \mathrm{b}}$ & $104 \pm 15$ \\
\hline & Moving & $130 \pm 14^{\mathrm{a}, \mathrm{b}}$ & $327 \pm 51^{\mathrm{a}}$ & $285 \pm 25^{\mathrm{a}}$ & $281 \pm 38$ \\
\hline
\end{tabular}

a Values for activities that were statistically different from those measured in the wake state

${ }^{\mathrm{b}}$ Values for temperatures that were statistically different from those measured at $27{ }^{\circ} \mathrm{C}$

reduction in the predominant frequency band of the EEG with the transition from wake to sleep in reptiles (Walker and Berger 1973; Warner and Huggins 1978; Meglasson and Huggins 1979; Huntley 1987) others, like us, have also reported the presence of slow waves in awake animals (Tauber et al. 1968; Rial et al. 1993; De Vera et al. 1994). High amplitude spikes (believed to be of cortical origin) have also been reported to be an indicator of behavioral quiescence and sleep in reptiles (Flanigan 1973; Flanigan et al. 1973; Walker and Berger 1973), while others report these spikes only during wake (Tauber et al. 1968; Huntley 1987; De Vera et al. 1994). We observed them during both wake and sleep. In summary, our data suggest that while there is an overall decline in brain and muscle activity from the alert to sleep state, this is not accompanied by prolonged periods of synchronized activity, distinct EEG frequencies or unique high frequency spikes. As a result, we reasoned that using EEG/EMG criteria as markers of the wake-sleep transition did not contribute more than monitoring metabolic and cardio-respiratory variables alone (see next section).

\section{Metabolic and cardio-respiratory changes with activity and temperature}

Mass specific rates of $\mathrm{O}_{2}$ consumption and $\mathrm{CO}_{2}$ production in our study are in good agreement with values reported 


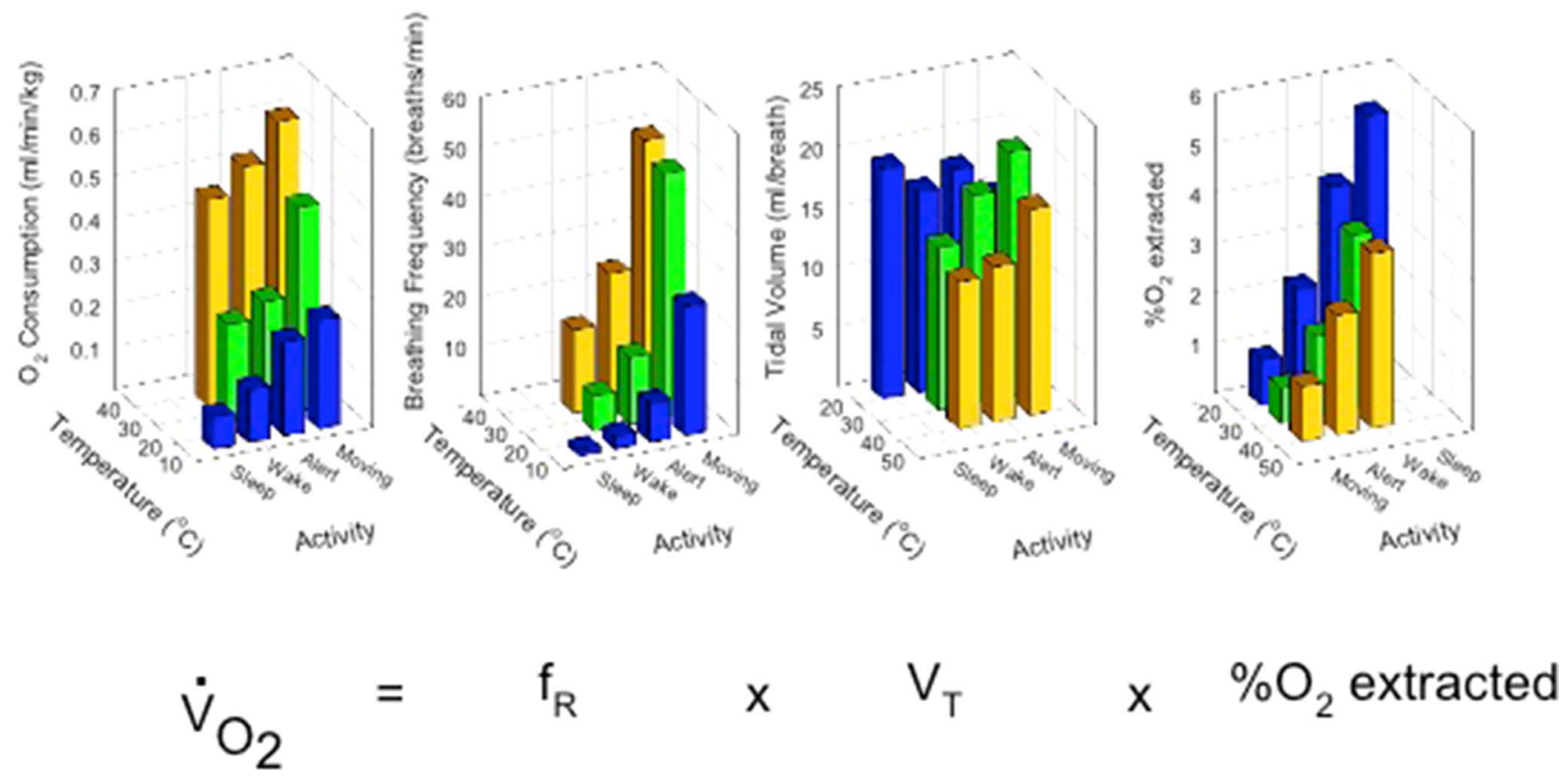

Fig. 5 Mean values of each variable in Fick's equation for oxygen transport by ventilatory convection (rate of oxygen consumption $=$ breathing frequency $\times$ tidal volume $\times \mathrm{O}_{2}$ extraction from the lung) as a function of temperature and activity state (see Table 1 for statistics)

Table $2 Q_{10}$ values of directly measured variables in Series 2

\begin{tabular}{lllll}
\hline Variable & Activity & $17-27^{\circ} \mathrm{C}$ & $27-37{ }^{\circ} \mathrm{C}$ & $17-37{ }^{\circ} \mathrm{C}$ \\
\hline Oxygen consumption & Sleep & - & - & - \\
& Quiet & $2.3 \pm 0.8$ & $2.4 \pm 0.8$ & $2.1 \pm 0.2$ \\
& Alert & $1.3 \pm 0.1$ & $2.1 \pm 0.3$ & $1.6 \pm 0.1$ \\
& Moving & $1.9 \pm 0.2$ & $1.4 \pm 0.2$ & $1.6 \pm 0.1$ \\
$\mathrm{CO}_{2}$ production & Sleep & - & - & - \\
& Quiet & $2.3 \pm 0.4$ & $1.7 \pm 0.2$ & $1.9 \pm 0.2$ \\
& Alert & $1.7 \pm 0.3$ & $1.6 \pm 0.3$ & $1.5 \pm 0.1$ \\
Heart rate & Moving & $1.8 \pm 0.2$ & $1.3 \pm 0.2$ & $1.5 \pm 0.1$ \\
& Sleep & - & - & - \\
& Quiet & $2.0 \pm 0.3$ & $2.5 \pm 0.5$ & $2.2 \pm 0.1$ \\
& Alert & $2.5 \pm 0.6$ & $2.2 \pm 0.4$ & $2.2 \pm 0.2$ \\
Breathing frequency & Moving & $3.4 \pm 0.3$ & $1.5 \pm 0.1$ & $2.2 \pm 0.1$ \\
& Sleep & - & - & - \\
& Quiet & $2.9 \pm 0.5$ & $2.4 \pm 0.6$ & $2.6 \pm 0.1$ \\
& Alert & $2.2 \pm 0.6$ & $2.0 \pm 0.3$ & $2.0 \pm 0.2$ \\
& Moving & $1.9 \pm 0.2$ & $1.1 \pm 0.1$ & $1.4 \pm 0.1$ \\
\hline
\end{tabular}

in the literature (Andrade and Abe 1999; Skovgaard and Wang 2004; Toledo et al. 2008; Milsom et al. 2008). The mean values of $f_{\mathrm{H}}, f_{\mathrm{R}}$, and $V_{\mathrm{T}}$ presented here are also similar to those previously reported for tegu lizards at similar temperatures and activity states (Andrade and Abe 1999; Klein et al. 2003; Skovgaard and Wang 2004). The ranges reported in the literature are large, however, as metabolism varies seasonally in this species, with standard metabolism in the spring and summer being significantly greater (up to three times) than in the autumn or winter (Andrade and Abe 1999; de Souza et al. 2004; Toledo et al. 2008; Milsom et al. 2008).

\section{Effects of temperature}

Because tegu lizards are ectotherms, we had anticipated that all physiological rate processes, including $\dot{V}_{\mathrm{O}_{2}}, \dot{V}_{\mathrm{CO}_{2}}$, $f_{\mathrm{H}}$, and $f_{\mathrm{R}}$, would increase with ambient temperature and this was the case. Our data show that there was no consistent difference between $Q_{10}$ values calculated over the 17-27 ${ }^{\circ} \mathrm{C}$ range, the $27-37{ }^{\circ} \mathrm{C}$ range, or the full temperature range of $17-37{ }^{\circ} \mathrm{C}$. All values were close to 2.0. Reptiles in general have $Q_{10}$ values ranging from 1.5 to 3.1 for metabolic processes (Bennett and Dawson 1976).

\section{Effects of activity state}

Unfortunately, only the "quiet wake", "alert" and "moving" states could be compared in Series 2 since no sleep occurred at the two higher temperatures and only a few lizards exhibited evidence of sleep at the lowest temperature. However, the trends seen in Series 2 were similar to those seen in Series 1 where data were obtained for "sleep", "wake" and "alert" states. Analysis of both data sets suggests that while it is difficult to distinguish sleep from wake by monitoring electrophysiological variables (EEG and EMG) these behavioral states can be distinguished clearly 

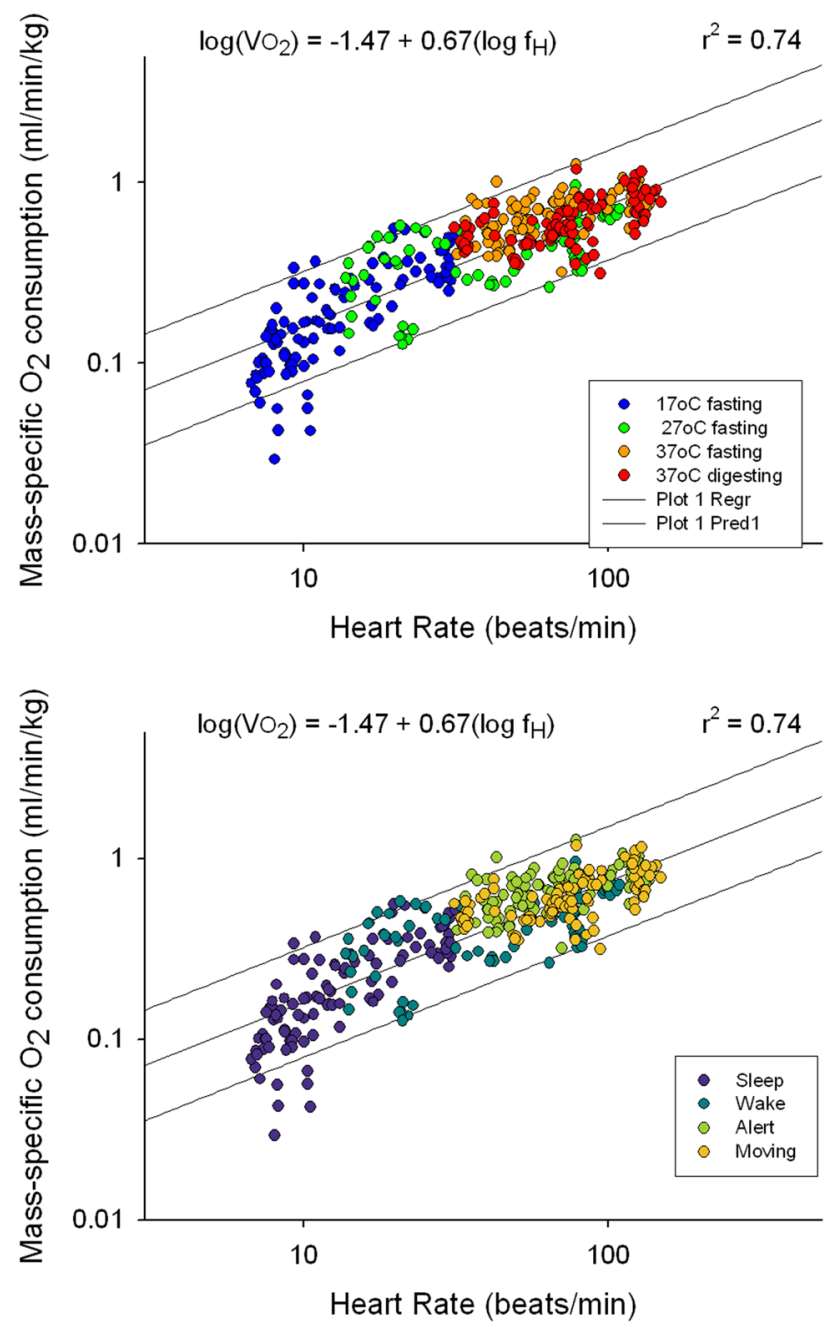

Fig. 6 Heart rate plotted as a function of mass-specific oxygen consumption color coded by temperature (a) and activity (b). The best-fit linear regression is shown along with the $95 \%$ prediction intervals, the regression equation, and the $r^{2}$ value for the regression

Table 3 Regression variables and estimation of fit $\left(r^{2}\right)$ for mass-specific oxygen consumption vs heart rate data

\begin{tabular}{llllll}
\hline$x$ & $y$ & Slope & Intercept & SEE & $r^{2}$ \\
\hline$f_{\mathrm{H}}$ & $s \dot{V}_{\mathrm{O}_{2}}$ & $0.007 \pm 0.000$ & $0.197 \pm 0.014$ & 0.148 & 0.663 \\
$\ln f_{\mathrm{H}}$ & $s \dot{V}_{\mathrm{O}_{2}}$ & $0.242 \pm 0.008$ & $-0.334 \pm 0.029$ & 0.139 & 0.704 \\
$\ln f_{\mathrm{H}}$ & $\ln s \dot{V}_{\mathrm{O}_{2}}$ & $0.669 \pm 0.021$ & $-3.184 \pm 0.074$ & 0.357 & 0.735 \\
\hline
\end{tabular}

Simple linear regressions were calculated for pooled untransformed and pooled transformed data. SEE represents the standard error of the estimate. All regressions were significant. $(N=380)$

based on the metabolic and cardio-respiratory changes. Thus, even though lizards remain motionless in all of the behavioral states of "sleep", "wake" and "alert", each state is associated with significantly different levels of
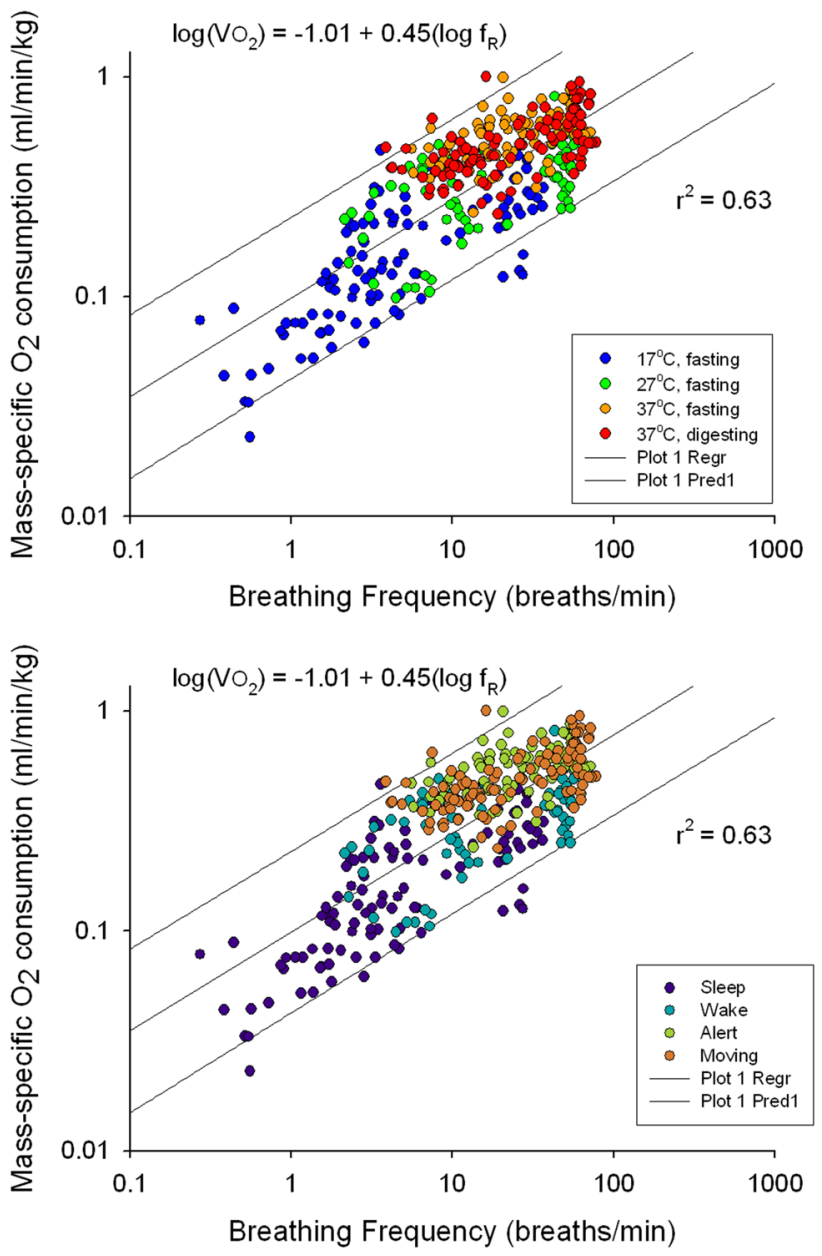

Fig. 7 Breathing Frequency plotted as a function of mass-specific oxygen consumption color coded by temperature (a) and activity (b). The best-fit linear regression is shown along with the $95 \%$ prediction intervals, the regression equation, and the $r^{2}$ value for the regression

metabolism, heart rate and breathing frequency presumably associated with changes in resting muscle tone and other physiological changes.

\section{The correlation between heart rate and metabolic rate}

Studies designed to address specific questions about metabolic depression during seasonal dormancy in animals under field conditions are challenged by the need to determine metabolic rates in unrestrained free ranging animals. The time energy budget method is one technique that may be used in the wild that estimates daily metabolic expenditure from the proportion of time the animal spends performing different activities. This method of estimating metabolic rate requires energy costs of various activities to be predetermined by laboratory techniques and demands that the animal being studied is constantly monitored (Ettinger and King 1980; Bevan et al. 1994). In recent years, there 
Table 4 Regression variables and estimation of fit $\left(r^{2}\right)$ for mass-specific oxygen consumption vs breathing rate data

\begin{tabular}{llllll}
\hline$x$ & $y$ & Slope & Intercept & SEE & $r^{2}$ \\
\hline$f_{\mathrm{R}}$ & $s \dot{V}_{O_{2}}$ & $0.008 \pm 0.000$ & $0.301 \pm 0.015$ & 0.190 & 0.449 \\
$\ln f_{\mathrm{R}}$ & $s \dot{V}_{O_{2}}$ & $0.154 \pm 0.007$ & $0.086 \pm 0.021$ & 0.171 & 0.554 \\
$\ln f_{\mathrm{R}}$ & $\ln s \dot{V}_{O_{2}}$ & $0.439 \pm 0.018$ & $-2.058 \pm 0.053$ & 0.431 & 0.631 \\
\hline
\end{tabular}

Simple linear regressions were calculated for pooled untransformed and pooled transformed data. SEE represents the standard error of the estimate. All regressions were significant. $(N=380)$

have been numerous studies demonstrating that heart rate can be used as a reliable indicator of metabolic rate under field conditions as long as certain criteria are met (Butler 1993; Bevan et al. 1995; Green et al. 2001; Froget et al. 2002; Butler et al. 1992; Green and Frappell 2007; Green et al. 2008), thus offering an alternative to the time energy budget method. The heart rate method has been best studied in mammals and birds and faces additional challenges in ectothermic animals, such as large fluctuations in body temperature and modifications in heart rate for thermoregulatory purposes (Clark et al. 2006). The heart rate method may be used reliably, however, if temperature effects and the effects of feeding are taken into account (Butler et al. 2002; Clark et al. 2005a, 2006).

The basis of the heart rate method for estimating metabolic rate lies in Fick's convection equation for the circulatory system, which can be written as:

$\dot{V}_{\mathrm{O}_{2}}=f_{H} \times V_{\mathrm{s}} \times\left(\mathrm{O}_{2 \mathrm{a}}-\mathrm{O}_{2 \mathrm{v}}\right)$

where $\dot{V}_{\mathrm{O}_{2}}$ is the rate of oxygen consumption, $f_{\mathrm{H}}$ is the heart rate, $\mathrm{V}_{\mathrm{s}}$ is the cardiac stroke volume, and $\left(\mathrm{O}_{2 \mathrm{a}}-\mathrm{O}_{2 \mathrm{v}}\right)$ is the oxygen content difference between arterial and venous blood. The product of $V_{\mathrm{s}}$ and $\left(\mathrm{O}_{2 \mathrm{a}}-\mathrm{O}_{2 \mathrm{v}}\right)$ is termed the cardiac $\mathrm{O}_{2}$ pulse and represents the amount of oxygen taken up by the tissues per heartbeat. If changes in the rate of oxygen consumption are mediated primarily by changes in heart rate (assuming the cardiac $\mathrm{O}_{2}$ pulse changes in a constant or curvilinear fashion with respect to changing oxygen consumption), $f_{\mathrm{H}}$ and $\dot{V}_{\mathrm{O}_{2}}$ will co-vary in a predictable, linear manner.

Activity: The relationship between $f_{\mathrm{H}}$ and $\dot{V}_{\mathrm{O}_{2}}$ at a given $T_{\mathrm{b}}$ for any given activity over a range of intensities is generally rectilinear or curvilinear in birds, (Grubb et al. 1983; Bevan et al. 1994; Green et al. 2001; Ward et al. 2002) mammals (Fedak et al. 1988; Williams et al. 1991, 1993), reptiles (Bennett 1972; Gleeson et al. 1980; Frappell et al. 2002; Butler et al. 2002; Clark et al. 2006) and some fish (Armstrong 1986; Lucas 1994; Webber et al. 1998; Clark et al. 2005a). Thus, for most vertebrates, the cardiac $\mathrm{O}_{2}$ pulse changes systematically during any activity such that a strong relationship between $f_{H}$ and $\dot{V}_{\mathrm{O}_{2}}$ is maintained
(Wilson 1974; Gleeson et al. 1980; Grubb et al. 1983; Butler et al. 1992; Clark et al. 2005a, b). However, this has not always been the case when comparing the $f_{\mathrm{H}} / \dot{V}_{\mathrm{O}_{2}}$ relationship between different activities. For example, barnacle geese and bar-headed geese displayed a different $f_{\mathrm{H}} / \dot{V}_{\mathrm{O}_{2}}$ relationship (different slopes and intercepts) when walking/ running on a treadmill compared with flying in a wind tunnel (Ward et al. 2002) and king penguins displayed a different $f_{\mathrm{H}} / \dot{V}_{\mathrm{O}_{2}}$ relationship when walking/running on a treadmill compared to thermoregulating at low environmental temperatures (Froget et al. 2002). Tegu lizards in the present study, however, retained the same $f_{\mathrm{H}} / \dot{V}_{\mathrm{O}_{2}}$ relationship between the activity states we have defined as sleep, quiet wake, alert and moving.

Temperature: For some species of fish (Claireaux et al. 1995; Clark et al. 2005a), as well as for marine iguanas (Butler et al. 2002) and Rosenberg's goanna (Clark et al. 2003, 2006), increases in temperature caused a right shift in the linear regression that described the relationship between $f_{\mathrm{H}}$ and $\dot{V}_{\mathrm{O}_{2}}$. This was true for animals at rest as well as during exercise and recovery and was also true during feeding in the goanna (Clark et al. 2006). Thus, for most vertebrates, the cardiac $\mathrm{O}_{2}$ pulse changes systematically during exercise and proportionally across temperature such that a strong relationship between $f_{\mathrm{H}}$ and $\dot{V}_{\mathrm{O}_{2}}$ is maintained (Wilson 1974; Gleeson et al. 1980; Grubb et al. 1983; Butler et al. 1992; Clark et al. 2005a, b). As a consequence, a common equation can be used to relate $f_{\mathrm{H}}$ and $\dot{V}_{\mathrm{O}_{2}}$ as long as a factor correcting for body temperature is included (Butler et al. 2002; Clark et al. 2006). This was not necessary in the case of the tegu lizards as the relationship between $f_{\mathrm{H}}$ and $\dot{V}_{\mathrm{O}_{2}}$ remained constant for all activity levels across all temperatures. The effects of temperature and activity state were to extend a common relationship along a single curve.

\section{The correlation between breathing frequency and metabolic rate}

Since the Fick equation can also be described in terms of breathing frequency it seemed reasonable to consider whether $f_{\mathrm{R}}$ might be as good a proxy for metabolic rate as $f_{\mathrm{H}}$. The Fick's convection equation for ventilation can be written as:

$\dot{V}_{\mathrm{O}_{2}}=f_{\mathrm{R}} \times V_{\mathrm{T}}\left(\mathrm{FI}_{\mathrm{O} 2}-\mathrm{FE}_{\mathrm{O} 2}\right)$

where $\dot{V}_{\mathrm{O}_{2}}$ is the rate of oxygen consumption, $f_{R}$ is the breathing frequency, $V_{\mathrm{T}}$ is the tidal volume, and $\left(\mathrm{FI}_{\mathrm{O} 2}-\right.$ $\left.\mathrm{FE}_{\mathrm{O} 2}\right)$ is the difference in the fraction of oxygen in inspired and expired air. The product of $V_{\mathrm{T}}$ and $\left(\mathrm{FI}_{\mathrm{O} 2}-\mathrm{FE}_{\mathrm{O} 2}\right)$ is termed the ventilatory $\mathrm{O}_{2}$ pulse and represents the amount of oxygen extracted from inspired air per breath. In this case, if the product of $V_{\mathrm{T}}$ and $\left(\mathrm{FI}_{\mathrm{O} 2}-\mathrm{FE}_{\mathrm{O} 2}\right)$ also changes in a constant or curvilinear fashion with respect to changing 
oxygen consumption, breathing rate could also be used to estimate metabolic rate in the field (Hicks et al. 2000).

In all cases, however, the correlation coefficients for the regressions of $f_{\mathrm{R}}$ against $\dot{V}_{\mathrm{O}_{2}}$ turned out to be lower than those for the regressions of $f_{\mathrm{H}}$ against $\dot{V}_{\mathrm{O}_{2}}$. The differences were not great, however.

Again, the effects of temperature and activity state were to extend a common relationship along a single curve. Similar effects of temperature on ventilation have been shown for the ectotherms(Wood et al. 1977). While the correlation between $f_{\mathrm{R}}$ and metabolic rate may not be as tight as the correlation between $f_{\mathrm{H}}$ and metabolic rate, it may still be a useful alternative method for estimating $\dot{V}_{\mathrm{O}_{2}}$ when $f_{\mathrm{R}}$ can be measured but $f_{\mathrm{H}}$ can not.

\section{Predicting metabolic rates from energy budgets and heart rate/breathing rate}

Most studies in which the heart rate method has been validated against metabolic rate have achieved $r^{2}$ values around 0.8 and higher; that is, around $80 \%$ or more of the variation in $\dot{V}_{\mathrm{O}_{2}}$ could be explained by variations in $f_{\mathrm{H}}$. In the present study, the best $r^{2}$ values obtained were slightly lower, being 0.63 and 0.74 using $f_{\mathrm{R}}$ and $f_{\mathrm{H}}$ as predictors of metabolic rate, respectively. For these lizards, the predictive powers of $f_{\mathrm{R}}$ and $f_{\mathrm{H}}$ were maximized when the effects of changes in temperature, digestive state and activity were pooled. This reflects the uniform dependence of changes in metabolism, regardless of cause (temperature, digestive state or activity) on changes in $f_{\mathrm{R}}$ and $f_{\mathrm{H}}$ for increasing $\mathrm{O}_{2}$ delivery. In order to determine the extent to which the calibration equations derived in Series 2 could be used in tegu lizards in general, validation experiments must be performed using a different population of lizards. This remains to be done.

Finally, it is important to remember that the relationship between heart rate and metabolic rate may not remain constant in different seasons and physiological states. Amongst the various factors that have been shown to influence the relationship between $f_{H}$ and in various studies are: age, season, breeding state, and physical fitness (Thorarensen et al. 1996; Butler et al. 2000; Hawkins et al. 2000; Green et al. 2001; Froget et al. 2001; Butler et al. 2002; Clark et al. 2003; Fahlman et al. 2004). Thus, if either regression equation is to be used to predict metabolic rates of T. merianae in the field throughout the year, they should be used cautiously.

Acknowledgments This research was supported by grants from the Natural Sciences and Engineering Research Council of Canada to WKM and GJT, from the Conselho Nacional de Desenvolvimento Científico e Tecnológico (CNPq) to ASA, and DVA and from the Fundação de Amparo a Pesquisa do Estado de São Paulo (FAPESP) and Fundação para o Desenvolvimento da UNESP (FUNDUNESP) to DVA. We would also like to acknowledge the technical assistance of Colin Sanders to this study.

\section{References}

Abe AS (1983) Observations on dormancy in tegu lizards, Tupinambis teguixin (Reptilia, Teiidae). Naturalia 8:235-239

Abe AS (1995) Estivation in South American amphibians and reptiles. Braz J Med Biol Res 28:1241-1247

Andrade DV, Abe AS (1999) Gas exchange and ventilation during dormancy in the tegu lizard Tupinambis merianae. J Exp Biol 202:3677-3685

Armstrong JD (1986) Heart rate as an indicator of activity, metabolic rate, food intake and digestion in pike, Esox lucius. J Fish Biol 29:207-221

Ayala-Guerrero F, Huitron-Resendiz S (1991) Sleep patterns in the lizard Ctenosaura pectinata. Physiol Behav 49:1305-1307

Ayala-Guerrero F, Calderon A, Perez MC (1988) Sleep patterns in a chelonian reptile (Gopherus flavomarginatus). Physiol Behav 44:333-337

Bennett AF (1972) The effect of activity on oxygen consumption, oxygen debt, and heart rate in the lizards Varanus gouldii and Sauromalus hispidus. J Comp Physiol B 79:259-280

Bennett AF, Dawson WR (1976) Metabolism. In: Gans C, Dawson WR (eds) Biology of the reptilia. Academic Press, London, pp $127-223$

Bevan R, Woakes A, Butler P, Boyd I (1994) The use of heart rate to estimate oxygen consumption of free-ranging black-browed albatrosses, Diomedea melanophrys. J Exp Biol 193:119-137

Bevan RM, Speakman JR, Butler PJ (1995) Daily energy expenditure of tufted ducks: a comparison between indirect calorimetry, doubly labelled water and heart rate. Funct Ecol 9:40-47

Butler PJ (1993) To what extent can heart rate be used as an indicator of metabolic rate in free-living marine mammals? In: Boyd IL (ed) Recent advances in marine mammal science. Oxford University Press, Oxford, pp 317-332

Butler P, Woakes A, Boyd I, Kanatous S (1992) Relationship between heart rate and oxygen consumption during steady-state swimming in California sea lions. J Exp Biol 170:35-42

Butler PJ, Woakes AJ, Bevan RM, Stephenson R (2000) Heart rate and rate of oxygen consumption during flight of the barnacle goose, Branta leucopsis. Comp Biochem Physiol A 126:379-385

Butler PJ, Frappell PB, Wang T, Wikelski M (2002) The relationship between heart rate and rate of oxygen consumption in Galapagos marine iguanas (Amblyrhynchus cristatus) at two different temperatures. J Exp Biol 205:1917-1924

Claireaux G, Webber DM, Kerr SR, Boutilier RG (1995) Physiology and behaviour of free-swimming Atlantic cod (Gadus morhua) facing fluctuating temperature conditions. J Exp Biol 198:49-60

Clark TD, Butler PJ, Frappell PB (2003) The relationship between body temperature, heart rate and rate of oxygen consumption in Rosenberg's goanna (Varanus rosenbergi) at various levels of activity is affected by time in captivity. Comp Biochem Physiol A 134:S22

Clark TD, Ryan T, Ingram BA, Woakes AJ, Butler PJ, Frappell PB (2005a) Factorial aerobic scope is independent of temperature and primarily modulated by heart rate in exercising Murray cod (Maccullochella peelii peelii). Physiol Biochem Zool 78:347-355

Clark TD, Wang T, Butler PJ, Frappell PB (2005b) Factorial scope of cardio-metabolic variables remains constant with changes in body temperature in the varanid lizard, Varanus rosenbergi. Am J Physiol 288:R992-R997

Clark TD, Butler PJ, Frappell PB (2006) Factors influencing the prediction of metabolic rate in a reptile. Funct Ecol 20:105-113

de Souza SCR, de Carvalho JE, Abe AS, Bicudo JEPW, Bianconcini MSC (2004) Seasonal metabolic depression, substrate utilisation 
and changes in scaling patterns during the first year cycle of tegu lizards (Tupinambis merianae). J Exp Biol 207:307-318

De Vera L, Gonzalez J, Rial RV (1994) Reptilian waking EEG: slow waves, spindles and evoked potentials. Electroenecphalogr Clin Neurophysiol 90:298-303

Ettinger AO, King JR (1980) Time and energy budgets of the Willow Flycatcher (Empidonax traillii) during the breeding season. Auk 97:533-546

Fahlman A, Handrich Y, Woakes AJ, Bost CA, Holder R, Duchamp C, Butler PJ (2004) Effect of fasting on the $V \mathrm{O}_{2}-f_{\mathrm{H}}$ relationship in king penguins, Aptenodytes patagonicus. Am J Physiol 287:R870-R877

Fedak MA, Pullen MR, Kanwisher J (1988) Circulatory responses of seals to periodic breathing: heart rate and breathing during exercise and diving in the laboratory and open sea. Can J Zool 66:53-60

Flanigan WF (1973) Sleep and wakefulness in Iguanid lizards, Ctenosaura pectinata and Iguana iguana. Brain Behav Evol 8:401-436

Flanigan WF, Wilcox RH, Rechtschaffen A (1973) The EEG and behavioural continuum of the crocodilian Caiman sclerops. Electroencephalogr Clin Neurophysiol 43:521-538

Frappell PB, Schultz TJ, Christian KA (2002) Oxygen transfer during aerobic exercise in a varanid lizard Varanus mertensi is limited by the circulation. J Exp Biol 205:2725-2736

Froget G, Butler P, Handrich Y, Woakes A (2001) Heart rate as an indicator of oxygen consumption: influence of body condition in the king penguin. J Exp Biol 204:2133-2144

Froget G, Handrich Y, Le Maho Y, Rouanet J-L, Woakes A, Butler P (2002) The heart rate/oxygen consumption relationship during cold exposure of the king penguin: a comparison with that during exercise. J Exp Biol 205:2511-2517

Glass ML, Wood SC, Johansen K (1978) The application of pneumotachography on small unrestrained animals. Comp Biochem Physiol 59A:425-427

Gleeson TT, Mitchell GS, Bennett AF (1980) Cardiovascular responses to graded activity in the lizards Varanus and Iguana. Am J Physiol 239:R174-R179

Green JA, Frappell PB (2007) Improving the precision and accuracy of estimates made using the heart rate method. Physiol Biochem Zool 80:551-555

Green J, Butler P, Woakes A, Boyd I, Holder R (2001) Heart rate and rate of oxygen consumption of exercising macaroni penguins. $\mathrm{J}$ Exp Biol 204:673-684

Green JA, Frappell PB, Clark TD, Butler PJ (2008) Predicting rate of oxygen consumption from heart rate while little penguins work rest and play. Comp Biochem Physiol 150A:222-230

Grubb B, Jorgensen DD, Conner M (1983) Cardiovascular changes in the exercising emu. J Exp Biol 104:193-201

Hawkins P, Butler P, Woakes A, Speakman J (2000) Estimation of the rate of oxygen consumption of the common eider duck (Somateria mollissima), with some measurements of heart rate during voluntary dives. J Exp Biol 203:2819-2832

Hicks JW, Riedesel ML (1983) Diurnal ventilatory patterns in the garter snake, Thamnophis elegans. J Comp Physiol 149:503-510

Hicks JW, Wang T, Bennett AF (2000) Patterns of cardiovascular and ventilatory response to elevated metabolic states in the lizard Varanus exanthematicus. J Exp Biol 203:2437-2445

Huntley AC (1987) Electrophysiological and behavioral correlates of sleep in the desert iguana Dipsosaurus dorsalis Hallowell. Comp Biochem Physiol 86A:325-330

Klein W, Andrade DV, Abe AS, Perry SF (2003) Role of the posthepatic septum on breathing during locomotion in Tupinambis merianae (Reptilia: Teiidae). J Exp Biol 206:2135-2143
Klein W, Perry SF, Abe AS, Andrade DV (2006) Metabolic response to feeding in Tupinambis merianae: circadian rhythm and possible respiratory constraint. Physiol Biochem Zool 79:593-601

Lucas MC (1994) Heart rate as an indicator of metabolic rate and activity in adult Atlantic salmon, Salmo salar. J Fish Biol 44:889-903

Meglasson MD, Huggins SE (1979) Sleep in a crocodilian, Caiman sclerops. Comp Biochem Physiol 63A:561-567

Milsom WK, Andrade DV, BritoSP Toledo LF, Wang T, Abe AS (2008) Seasonal changes in daily metabolic patterns of tegu lizards (Tupinambis merianae) placed in the cold $\left(17^{\circ} \mathrm{C}\right)$ and dark. Physiol Biochem Zool 81:158-164

Rechtschaffen A, Kales A, Berger RJ, Dement WC, Jacobson A, Johnson LC, Jouvet M, Monroe LJ, Oswald I, Roffward HP, Roth B, Walter RD (1968) A manual of standardized terminology, techniques and scoring system for sleep stages of human subjects. US Government Printing Office, Washington, DC

Revell TK, Dunbar SG (2007) The energetic savings of sleep versus temperature in the Desert Iguan (Dipsosaurus dorsalis) at three ecologically relevant temperatures. Comp Biochem Phys A 148:393-398

Rial R, Nicolau MC, Lopez-Garcia JA, Almirall H (1993) Mini review: on the evolution of waking and sleeping. Comp Biochem Physiol 104A:189-193

Skovgaard N, Wang T (2004) Cost of ventilation and effect of digestive state on the ventilatory response of the tegu lizard. Respir Physiol Neurobiol 141:85-97

Tauber ES, Rojas-Ramirez J, Peon RH (1968) Electrophysiological and behavioral correlates of wakefulness and sleep in the lizard, Ctenosaura pectinata. Electroencephalogr Clin Neurophysiol 24:424-433

Thorarensen H, Gallaugher PE, Farrell AP (1996) The limitations of heart rate as a predictor of metabolic rate in fish. J Fish Biol 49:226-236

Toledo LF, Brito SP, Milsom WK, Abe AS, Andrade DV (2008) Effects of changes in season, temperature and body mass on the standard metabolic rate of tegu lizards (Tupinambis merianae). Physiol Biochem Zool 81:165-175

Walker JM, Berger RJ (1973) A polygraphic study of the tortoise (Testudo denticulata): absence of electrophysiological signs of sleep. Brain Behav Evol 8:453-467

Wang T, Warburton SJ (1995) Breathing pattern and cost of ventilation in the American alligator. Respir Physiol 102:29-37

Ward S, Bishop CM, Woakes AJ, Butler PJ (2002) Heart rate and the rate of oxygen consumption of flying and walking barnacle geese (Branta leucopsis) and bar-headed geese (Anser indicus). J Exp Biol 205:3347-3356

Warner BF, Huggins SE (1978) An electroencephalographic study of sleep in young caiman in a colony. Comp Biochem Physiol 59A: $139-144$

Webber DM, Boutilier RG, Kerr SR (1998) Cardiac output as a predictor of metabolic rate in cod Gadus morhua. J Exp Biol 201:2779-2789

Williams TM, Kooyman GL, Croll DA (1991) The effect of submergence on heart rate and oxygen consumption of swimming seals and sea lions. J Comp Physiol 160:637-644

Williams TM, Friedl WA, Haun JE (1993) The physiology of bottlenose dolphins (Tursiops truncatus) - heart rate, metabolic rate and plasma lactate concentration during exercise. J Exp Biol 179:31-46

Wilson KJ (1974) The relationship of oxygen supply for activity to body temperature in four species of lizards. Copeia 1974:920-934

Withers PC (1977) Measurement of $\mathrm{VO}_{2}, \mathrm{VCO}_{2}$, and evaporative water loss with a flow -through mask. J Appl Physiol 42:120-123 
Wood SC, Glass ML, Johansen K (1977) Effects of temperature on respiration and acid base balance in a monitor lizard. J Comp Physiol B 116:287-296
Wood SC, Johansen K, Glass ML, Maloiy GMD (1978) Aerobic metabolism of the lizard Varanus exanthematicus: effects of activity, temperature and size. J Comp Physiol B 127:331-336 